\title{
Oxidative modification of human ceruloplasmin induced by a catechol neurotoxin, salsolinol
}

\author{
Seung-Sub Kim ${ }^{1}$, Jae Yoon $\mathrm{Kang}^{2}$ \& Jung Hoon Kang ${ }^{1, *}$ \\ ${ }^{1}$ Department of Biomedical Science, Cheongju University, Cheongju 28160, ${ }^{2}$ School of Interdisciplinary Studies, Korea University, Seoul \\ 02841, Korea
}

\begin{abstract}
Salsolinol (SAL), a compound derived from dopamine metabolism, is the most probable neurotoxin involved in the pathogenesis of Parkinson's disease (PD). In this study, we investigated the modification and inactivation of human ceruloplasmin (hCP) induced by SAL. Incubation of hCP with SAL increased the protein aggregation and enzyme inactivation in a dose-dependent manner. Reactive oxygen species scavengers and copper chelators inhibited the SAL-mediated hCP modification and inactivation. The formation of dityrosine was detected in SAL-mediated hCP aggregates. Amino acid analysis post the exposure of $\mathrm{hCP}$ to SAL revealed that aspartate, histidine, lysine, threonine and tyrosine residues were particularly sensitive. Since hCP is a major copper transport protein, oxidative damage of hCP by SAL may induce perturbation of the copper transport system, which subsequently leads to deleterious conditions in cells. This study of the mechanism by which ceruloplasmin is modified by salsolinol may provide an explanation for the deterioration of organs under neurodegenerative disorders such as PD. [BMB Reports 2016; 49(1): 45-50]
\end{abstract}

\section{INTRODUCTION}

Parkinson's disease (PD) is a neurodegenerative disease characterized by the degeneration of dopaminergic neurons in the substantia nigra of the midbrain $(1,2)$. Salsolinol (1-methyl6,7-dihydroxy-1,2,3,4-tetrahydroisoquinoline; SAL) specifically affects the nigrostriatal dopamine system. Previous studies show that it may participate in the pathogenesis of PD (3-6). In the brain, SAL can be endogenously synthesized from dopamine and acetaldehyde, either by SAL synthase or PictetSpengler reaction $(7,8)$. As the oxidative stress level increases, the lipid peroxidation-induced formation of acetaldehyde can promote the synthesis of SAL in dopaminergic cells (9-12).

${ }^{*}$ Corresponding author. Tel: +82-43-229-8562; Fax: +82-43-2328799; E-mail: jhkang@cju.ac.kr

http://dx.doi.org/10.5483/BMBRep.2016.49.1.103

Received 27 May 2015, Revised 4 June 2015, Accepted 12 June 2015

Keywords: Ceruloplasmin, Copper, Reactive oxygen species, Salsolinol
Increased concentrations of SAL induce the mitochondrial toxicity (13). Subsequently, the increased SAL levels will elevate cellular oxidative stress by releasing reactive oxygen species (ROS) from the damaged mitochondria $(14,15)$, thus impairing the antioxidant defense mechanisms, such as superoxide dismutase (SOD) (16).

Human ceruloplasmin (hCP) is a copper-containing protein found in blood plasma, having ferroxidase activity as well as a possible role in iron metabolism. Oxidation of iron from ferrous to the ferric form occurs in the presence of hCP. In astrocytic foot processes, hCP is linked to glycophospho inositide (17). Mutations in the hCP gene can lead to aceruloplasminemia, a genetic disease characterized by iron overload in the basal ganglia (18). hCP may also play a role in the aggregation of $\alpha$-synuclein, a component of Lewy bodies; this has previously been confirmed in an in vitro study (19). Decreased hCP ferroxidase activity in cerebrospinal fluid (20-22) and serum (23-29) from idiopathic PD patients has also been reported. In addition, decreased hCP levels are associated with an earlier onset PD $(24,26,27)$.

In this study, the effects of SAL on the oxidative modifications of hCP were assessed. Our results demonstrated that SAL could induce hCP aggregation via free radical generation. Subsequently, the SAL-mediated hCP modification resulted in the release of copper from the protein.

\section{RESULTS AND DISCUSSION}

When incubated with SAL, the aggregation of hCP increased with increasing concentrations of SAL, in a dose-dependent manner (Fig. 1A and B). It is well known that all biological macromolecules are vulnerable to oxidative stress. Attack of various ROS on proteins can lead to amino acid modification and peptide bond cleavage. It has been reported that covalent cross-links involve both homologous and heterologous interactions between carbon-centered radical derivatives of identical or non-identical amino acid residues in two separate protein molecules (30). We investigated the protective effect of ROS scavengers on the aggregation of hCP induced by SAL. We found that incubation of hCP with SAL in the presence of ROS scavengers, such as, azide, formate and mannitol, prevented the aggregation of hCP (Fig. $1 \mathrm{C}$ and D).

ISSN: 1976-670X (electronic edition)

Copyright (C) 2016 by the The Korean Society for Biochemistry and Molecular Biology

(c) This is an open-access article distributed under the terms of the Creative Commons Attribution Non-Commercial License (http://creativecommons.org/licenses/by-nc/4.0) which permits unrestricted non-commercial use, distribution, and reproduction in any medium, provided the original work is properly cited. 
(A)

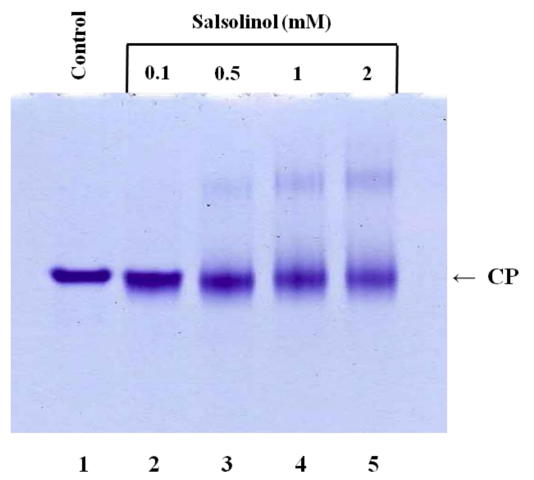

(C)

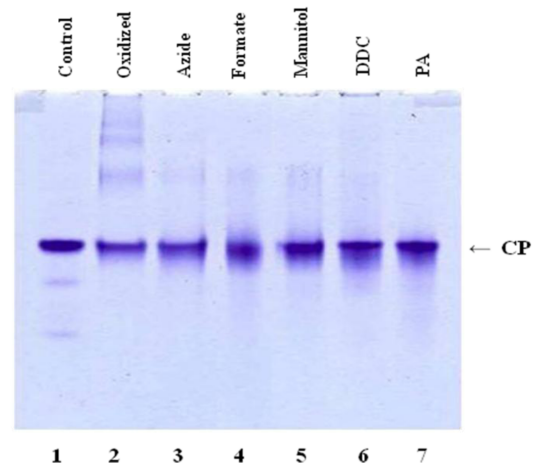

(A)

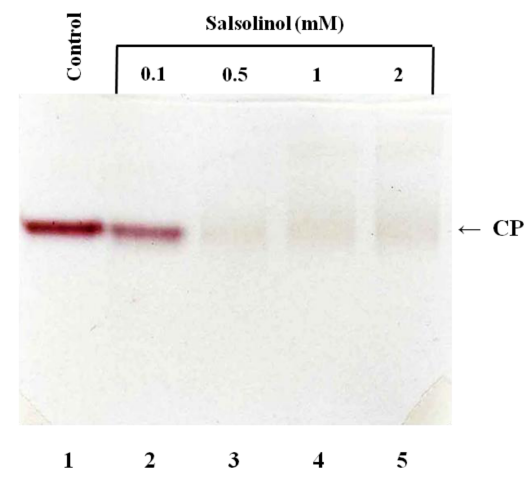

(C)

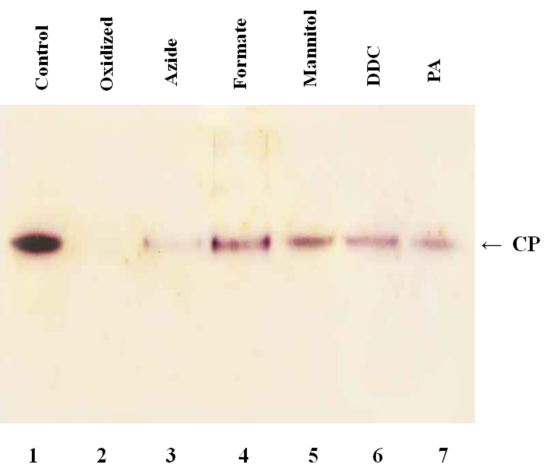

(B)

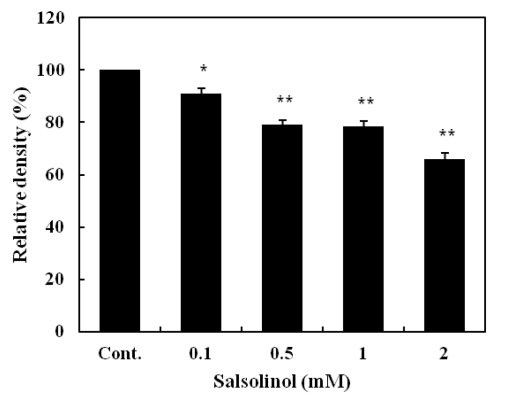

(D)

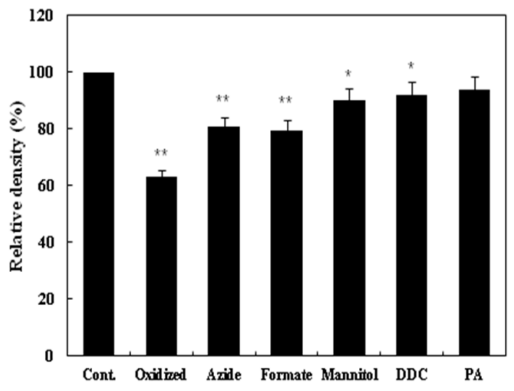

(B)

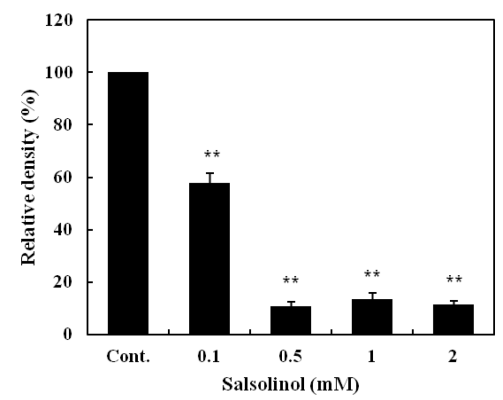

(D)

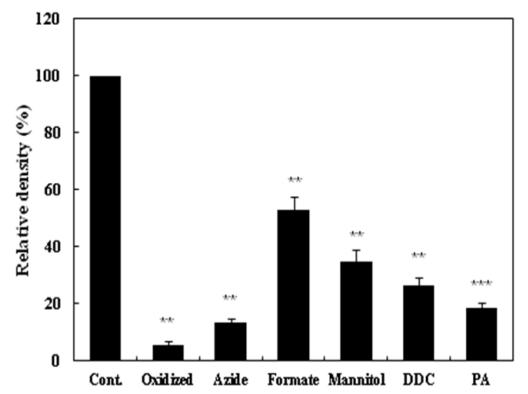

Fig. 1. Aggregation of hCP by $S A L$, and effect of ROS scavengers and copper chelators on SAL-mediated hCP aggregation. (A) $1.5 \mu \mathrm{M}$ hCP was incubated with various concentrations of $\mathrm{SAL}$ in $10 \mathrm{mM}$ phosphate buffer $(\mathrm{pH}$ $7.4)$, at $37^{\circ} \mathrm{C}$ for $24 \mathrm{~h}$. Reactions were stopped at the indicated time by freezing at $-80^{\circ} \mathrm{C}$. The pattern of protein bands was analyzed by native PAGE. (C) $1.5 \mu \mathrm{M}$ hCP was incubated with $2 \mathrm{mM} \mathrm{SAL}$ in $10 \mathrm{mM}$ phosphate buffer $(\mathrm{pH} 7.4)$, at $37^{\circ} \mathrm{C}$ for $24 \mathrm{~h}$, in the presence of ROS scavengers or copper chelators. Lane 1, hCP control; lane 2, oxidized hCP (without ROS scavenger); lane 3, $200 \mathrm{mM}$ azide: lane 4, $200 \mathrm{mM}$ formate; lane 5, 200 $\mathrm{mM}$ mannitol; lane 6, $1 \mathrm{mM}$ DDC; lane 7,1 mM PA. (B) and (D) Relative staining intensity of native PAGE gel was analyzed by densitometric scanning. Asterisk $(*)$ and double asterisks $(* *)$ denote statistical significance at $\mathrm{P}$ $<0.05$ and $\mathrm{P}<0.01$, respectively.

Fig. 2. Inactivation of hCP after incubation with SAL, and effect of ROS scavengers and copper chelators on SAL-mediated hCP inactivation. (A) 1.5 $\mu \mathrm{M}$ hCP was incubated with various concentrations of SAL in $10 \mathrm{mM}$ phosphate buffer $(\mathrm{pH} 7.4)$, at $37^{\circ} \mathrm{C}$ for 24 h. Reactions were stopped at the indicated time by freezing at $-80^{\circ} \mathrm{C}$. Activity of hCP was analyzed by activity staining method as described under "Materials and methods". (C) $1.5 \mu \mathrm{M}$ hCP was incubated with $2 \mathrm{mM}$ SAL in $10 \mathrm{mM}$ phosphate buffer $(\mathrm{pH} 7.4)$, at $37^{\circ} \mathrm{C}$ for $24 \mathrm{~h}$, in the presence of ROS scavengers or copper chelators. Lane 1, hCP control; lane 2, oxidized hCP (without ROS scavenger); lane 3, $200 \mathrm{mM}$ azide; lane 4, $200 \mathrm{mM}$ formate; lane 5, $200 \mathrm{mM}$ mannitol; lane 6, $1 \mathrm{mM}$ DDC; lane 7, $1 \mathrm{mM}$ PA. (B) and (D) Relative staining intensity of native PAGE gel was analyzed by densitometric scanning. Double asterisks $(* *)$ and triple asterisks $(* * *)$ denote statistical significance at $\mathrm{P}<0.01$ and $\mathrm{P}<0.001$, respectively. 
During the incubation of $\mathrm{hCP}$ with SAL, ferroxidase activity decreased when the concentration of SAL increased (Fig. 2A and $\mathrm{B}$ ), indicating that SAL-mediated hCP inactivation is closely associated with protein modification. Oxidative modification of metalloproteins may lead to a higher level of metal ions in cells $(31,32)$. A previous study has reported that oxidative modification of $\mathrm{Cu}, \mathrm{Zn}$-SOD can lead to inactivation and releasing copper from the enzyme (33). Since many proteins contain metal ions, especially trace metals such as copper and iron, subsequent exposure of them to $\mathrm{H}_{2} \mathrm{O}_{2}$ can generate ROS that selectively damage amino acid residues at the binding site (34). Another of our finding was that the ROS scavengers were partially able to prevent the inactivation of hCP (Fig. 2C and D).

Some aggregation of protein is due to the formation of 2,2' biphenyl cross-linkage of tyrosine residues (35). We investigated the formation of $\mathrm{O}, \mathrm{O}^{\prime}$-dityrosine during SAL-mediated hCP aggregation by measuring fluorescence emission spectrum at $410 \mathrm{~nm}$, with an excitation at $325 \mathrm{~nm}$. When hCP was treated with various concentrations of SAL, the formation of $\mathrm{O}, \mathrm{O}^{\prime}$-dityrosine cross-links increased with increasing concentrations of SAL (Fig. 3A). Our result suggests that the tyrosine-tyrosine cross-link formation might participate in SAL-mediated hCP aggregation.

Transition metals, such as iron and copper, are present in a variety of biological systems. When exposed to $\mathrm{H}_{2} \mathrm{O}_{2}$, they produce ROS, which damages the biological macromolecules (36-38). We investigated the protective effects of copper chelators, such as DDC and PA, on SAL-mediated hCP aggregation. When hCP was incubated with SAL in the presence of DDC and PA, the modification (Fig. 1C, lane 6 and 7) and inactivation (Fig. 2C, lane 6 and 7) of hCP were inhibited. Incubation of hCP with various concentrations of SAL induced the release of free copper ions from hCP (Fig. 3B). Transition metals can catalyze free radical reactions, such as autoxidations and hydroxyl radical formation. Therefore, hypothesize that the copper ions released from SAL-damaged hCP might have led to the formation of hydroxyl radicals in cells.

It has been reported that stable complexes can be formed by the reaction of catechol compounds with heavy metals such as iron or copper (39). Metal-catechol complexes may produce free radical compounds. Our results suggest that the deactivation of hCP by SAL might be due to the copper released from $\mathrm{hCP}$, or the formation of the SAL-Cu(II) complex. It is true that protein deactivation can be achieved by cross-linking of proteins with the ROS generated from reactions between catechol derivatives and/or heavy metal ions. However, it has also been reported that the deactivation of metallo-enzymes such as ribonucleotide reductase by catechol compounds, can be reversed by the addition of iron (40). Therefore, we hypothesize that $\mathrm{Cu}(\mathrm{II})-\mathrm{SAL}$ or $\mathrm{Cu}(\mathrm{II})-\mathrm{SAL}_{2}$ complex formation is the major mechanism involved in the deactivation of hCP or the release of copper from protein. Our results further suggest that the released copper can accelerate ROS formation, resulting in hCP aggregation.
To determine the target site against SAL on hCP, we analyzed the amino acid composition after acid and alkaline hydrolysis of the modified proteins. hCP exposure to SAL particularly resulted in the loss of aspartate, histidine, lysine, threonine and tyrosine residues (Fig. 4). hCP is comprised of six cupredoxin-type domains (41). Domains 1,3 and 5 comprise of 190 amino-acid residues. Domains 2, 4 and 6 possess a binding site for a mononuclear T1-type copper center (42). These even domains are smaller, with around 150 residues. The T1 sites in domains 4 and 6 are typical blue-copper sites, with two histidines and a cysteine ligand at around $2.0 \AA$, and a fourth weaker ligand, a methionine, at a distance of around $3.0 \AA$ (43). Our results suggest that copper binding sites are modified during the reaction of hCP with SAL; it can be re-

(A)

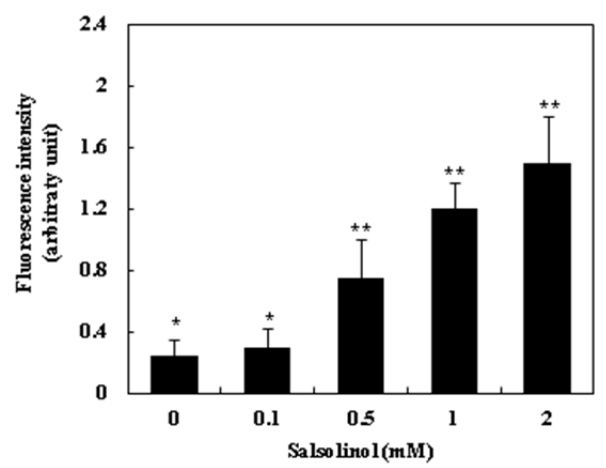

(B)

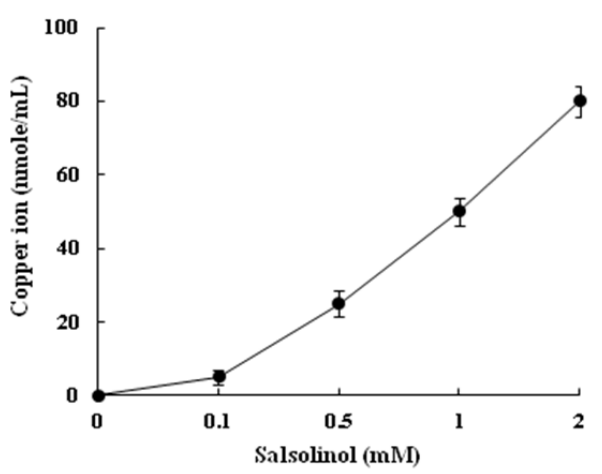

Fig. 3. Determination of dityrosine and released copper ions during incubation of hCP with SAL. The fluorescence spectra of dityrosine formation were observed when $1.5 \mu \mathrm{M}$ hCP was incubated with various concentrations of $\mathrm{SAL}$ in $10 \mathrm{mM}$ potassium phosphate buffer ( $\mathrm{pH} 7.4)$, at $37^{\circ} \mathrm{C}$ for $24 \mathrm{~h}$. (A) The fluorescence emission spectrum of the sample was monitored at $410 \mathrm{~nm}$ (excitation, $325 \mathrm{~nm}$ ) using a spectrofluorometer. (B) The free copper ions were determined with a colorimetric reagent using bathocuproine disulfonate. Asterisk $(*)$ and double asterisks $(* *)$ denote statistical significance at $\mathrm{P}<0.05$ and $\mathrm{P}<0.01$, respectively. 


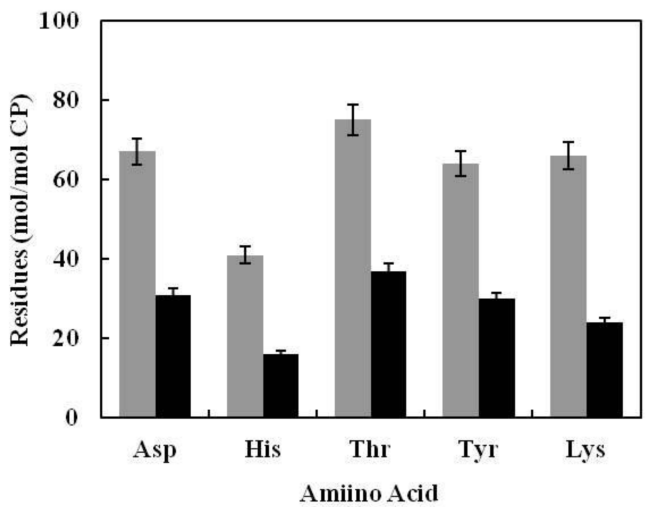

Fig. 4. Modification of amino acid residues in hCP by SAL. hCP was incubated in $10 \mathrm{mM}$ potassium phosphate buffer $(\mathrm{pH} 7.4)$, at $37^{\circ} \mathrm{C}$ under following conditions: $1.5 \mu \mathrm{M}$ hCP alone (gray bar); $1.5 \mu \mathrm{M}$ hCP plus $2 \mathrm{mM}$ SAL (dark bar). After incubation for 24 $h$, the amino acid composition of acid and alkaline hydrolysates was determined as described under "Materials and Methods".

leased from the oxidatively-damaged protein thus freeing copper from the ligand. Previous studies have similarly reported that the release of copper can be induced during the reaction of hCP with other oxidants at high concentrations (1-50 mM) $(44,45)$. Our results similarly revealed that SAL could lead to the modification of hCP and the release of copper ions at low concentrations (0.1-2 $\mathrm{mM})$. Taken together, these results suggest that the SAL-mediated hCP modification may be due to the oxidative damage resulting from ROS generated by two mechanisms: the autoxidation of SAL, and the Fenton-like reaction of free copper ions released from oxidatively-damaged hCP.

Alterations in iron homeostasis/metabolism can produce neurodegenerative diseases by multiple pathways. Copper released from the copper-binding proteins induced oxidative stress, which is caused to proceed to the degeneration of the substantia nigra in PD (46). The toxicity of SAL may be increased by the generation of ROS in the neurodegenerative disorder. Previous studies have been reported that SAL led to DNA cleavages in neuronal cells in the presence of transition metals $(47,48)$. It has also reported that SAL might increase ROS generation, and result in a reduction in the levels of glutathione in SH-SY5Y cells (49).

The concentration of SAL in the substantia nigra from normal control brains was determined to be $0.1 \mu \mathrm{M}$ (50). However, the concentration was found to be much higher in dopamine neuron. It was reported that SAL was selectively increased in the cerebrospinal fluid of patients with PD (51). In this study, we have used high concentrations of SAL. Although such values might be physiologically questionable, they demonstrated clear protein modifications when used at high concentrations, provoking protein damage in a relatively short period of time.
In conclusion, the findings of this study demonstrated that SAL could induce oxidative modification of hCP with subsequent copper release. This study also showed that this phenomenon involved free radical generation. Therefore, SAL-mediated hCP modification might be associated with the pathogenesis of PD, as well as other related disorders.

\section{MATERIALS AND METHODS}

\section{Materials}

The commercial hCP (Cabiochem) was further purified by gel filtration chromatography, using Superose 6 FPLC column (Pharmacia, Sweden). Salsolinol, azide, formate, mannitol, bathocuproine disulfonate, diethyldithio carbamic acid (DDC) and penicillamine (PA) were obtained from Sigma (St. Louis, MO, USA). Chelex 100 resin (sodium form) was obtained from Bio-Rad (Hercules, CA, USA). All solutions were treated with Chelex 100 resin to remove any traces of transition metal ions.

\section{Protein oxidative modification}

Protein concentrations were determined using the BCA method (52). $1.5 \mu \mathrm{M} \mathrm{hCP}$ modification was induced by incubating with SAL in a phosphate buffer $(\mathrm{pH} 7.4)$ at $37^{\circ} \mathrm{C}$. After incubation, the reaction mixtures were placed onto Vivaspin ultrafiltration spin column (Sartorius Stedim Biotech, Goettingen, German) and centrifuged for $1 \mathrm{~h}$ at 13,000 rpm to remove the SAL. The mixture was then washed with Chelex 100-treated water and centrifuged for $1 \mathrm{~h}$ at the same speed to remove any residual SAL. This procedure was repeated four times, after which the (washed) proteins were dried in a freeze-dryer and dissolved with $10 \mathrm{mM}$ potassium phosphate buffer $(\mathrm{pH}$ 7.4). The free radical scavenger-induced protection against the SAL-mediated hCP modification was performed by preincubating the enzyme with free radical scavengers for $5 \mathrm{~min}$ at room temperature, after which the mixture was reacted with SAL for $24 \mathrm{~h}$ at $37^{\circ} \mathrm{C}$. The unreacted reagent was then washed through a Microcon filter (Amicon).

\section{Analysis of CP aggregation}

The samples were treated with $4 \mu$ of concentrated sample buffer (0.25 M Tris, $40 \%$ glycerol, $0.01 \%$ bromophenolblue), and then subjected to polyacrylamide gel electrophoresis via the Laemmli method (53), using an $8 \%$ acrylamide slab gel. The gels were stained with $0.15 \%$ Coomassie Brilliant Blue R-250.

\section{Ceruloplasmin activity staining}

hCP activity staining was performed by the method of Sato and Gitlin (54). $1.5 \mu \mathrm{M}$ hCP was incubated with various concentrations of $\mathrm{SAL}$ in $10 \mathrm{mM}$ potassium phosphate buffer $(\mathrm{pH} 7.4)$, at $37^{\circ} \mathrm{C}$ for $24 \mathrm{~h}$. An aliquot of sample was subjected to native PAGE with a slab gel (stacking gel: $4 \%$ acrylamide; separating gel: $8 \%$ acrylamide). The gel was incubated in $0.1 \mathrm{M}$ sodium acetate buffer ( $\mathrm{pH}$ 5.7) containing $500 \mu \mathrm{g} / \mathrm{ml}$ of p-phenylenedi- 
amine, for $1 \mathrm{~h}$ at $37^{\circ} \mathrm{C}$ followed by washing in $50 \%$ ethanol.

\section{Detection of $0, \mathrm{O}^{\prime}$-dityrosine}

To detect $\mathrm{O}, \mathrm{O}^{\prime}$-dityrosine, $1.5 \mu \mathrm{M}$ hCP was incubated with various concentrations of $S A L$, in $10 \mathrm{mM}$ potassium phosphate ( $\mathrm{pH}$ 7.4). The fluorescence emission spectrum of the sample was then monitored at $410 \mathrm{~nm}$ (excitation, $325 \mathrm{~nm}$ ) using Spectrofluorometer SMF 25 (Bio-Tek Instruments).

\section{Determination of copper ion concentration}

The concentration of copper ions released from oxidatively damaged hCP was determined by using the bathocuproine disulfonate method, as described previously (55). The reaction mixture contained $1.5 \mu \mathrm{M} \mathrm{hCP}$ and various concentrations of $\mathrm{SAL}$, in a total volume of $100 \mu \mathrm{l}$, and incubated for $24 \mathrm{~h}$ at $37^{\circ} \mathrm{C}$. After incubation, the mixtures were placed into Vivaspin ultrafiltration spin columns (Sartorius Stedim Biotech, Goettingen, German) and centrifuged at 13,000 rpm for $1 \mathrm{~h}$. Colorimetric reagent was added into the filtrate and analyzed by a UV/VIS spectrophotometer (Shimadzu, UV-1601) at $535 \mathrm{~nm}$. The color reagent was composed of $1 \%$ ascorbate, $0.02 \%$ bathocuproine disulfonate and $1 \%$ acetic acid-acetate buffer $(\mathrm{pH} 4.5)$

\section{Amino acid analysis}

Aliquots of modified and native hCP were hydrolyzed at $110^{\circ} \mathrm{C}$ for $24 \mathrm{~h}$, after addition of $6 \mathrm{~N} \mathrm{HCl}$. Since amino acid hydrolysis destroys tryptophan, the tryptophan content of oxidized and native hCP preparations was determined by means of alkaline hydrolysis, as described previously (56). The amino acid content of acid and alkaline hydrolysates was determined by HPLC separation of their phenylisothiocyanate-derivatives, using the Waters Nova-Pak C18 column and HP 1100 detector (Hewlett Packard, USA).

\section{Statistical analysis}

Values are expressed as the means \pm S.D of three to five separate experiments. The statistical differences between the means were determined by the Student $t$-test.

\section{REFERENCES}

1. Olasode B, Niger JJ (2001) Idiopathic Parkinson's disease: a review of clinical types and pathology. Med 10, 116-120

2. Scott TR, Netsky MG (1961) The pathology of Parkinson's syndrome: a critical review. Int J Neurol 2, 51-60

3. Ikeda H, Markey CJ, Markey SP (1993) Search for neurotoxins structurally related to 1-methyl-4-phenylpyridine $(\mathrm{MPP}+)$ in the pathogenesis of Parkinson's disease. Brain Res 575, 285-298

4. Moser A, Kompf D (1992) Presence of methyl-6,7-dihydroxy-1,2,3,4-tetrahydroisoquinolines, derivatives of the neurotoxin isoquinoline, in parkinsonian lumbar CSF. Life Sciences 50, 1885-1891

5. Niwa T, Takeda T, Yoshizumi $\mathrm{H}$ et al (1991) Presence of 2-methyl-6,7-dihydroxy-1,2,3,4-tetrahydroisoqui-noline and 1,2-dimethyl-6,7-dihydroxy-1,2,3,4-tetrahydro-isoquinoline, novel endogenous amines, in parkinsonian and normal human brains. Biochem Biophys Res Commun 177, 603-609

6. Ohta S, Kohno M, Makino Y et al (1987) Tetrahydroisoquinoline and 1-methyl-tetrahydroisoquinoline are present in the human brain: relation to Parkinson's disease. Biomed Res 8, 453-456

7. Naoi M, Maruyama W, Akao $\mathrm{Y}$ and $\mathrm{Yi} H$ (2002) Dopamine-derived endogenous $\mathrm{N}$-methyl-(R)-salsolinol: its role in Parkinson's disease. Neurotoxicol Teratol 24, 579-591

8. Naoi M, Marayama W, Dostert P et al (1996) A novel enzyme enantio-selectively synthesizes (R)salsolinol, a precursor of a dopaminergic neurotoxin, $\mathrm{N}$-methyl(R)salsolinol. Neurosci Lett 212, 183-186

9. Deng Y, Luan Y, Qing H et al (2008) The formation of catechol isoquinolines in PC12 cells exposed to manganese. Neurosci Lett 444, 122-126

10. Jamal M, Ameno K, Ameno S et al (2003) In Vivo study of salsolinol produced by a high concentration of acetaldehyde in the striatum and nucleus accumbens of free-moving rats. Alcohol Clin Exp Res 27, 79S-84S

11. Jamal $M$, Ameno K, Kubota $T$ et al (2003) In vivo formation of salsolinol induced by high acetaldehyde concentration in rat striatum employing microdialysis. Alcohol Alcohol 38, 197-201

12. Wang R, Qing H, Liu XQ et al (2008) Iron contributes to the formation of catechol isoquinolines and oxidative toxicity induced by overdose dopamine in dopaminergic SH-SY5Y cells. Neurosci Bull 24, 125-132

13. Mravec B (2006) Salsolinol, a derivate of dopamine, is a possible modulator of catecholaminergic transmission: a review of recent developments. Physiol Res 55, 353-364

14. Wanpen S, Govitrapong P, Shavali S et al (2004) Salsolinol, a dopamine-derived tetrahydroisoquinoline, induces cell death by causing oxidative stress in dopaminergic $\mathrm{SH}-\mathrm{SY} 5 \mathrm{Y}$ cells, and the said effect is attenuated by metallothionein. Brain Res 1005, 67-76

15. Kang JH (2013) Salsolinol, a catechol neurotoxin, induces oxidative modification of cytochrome C. BMB Rep 46, 119-123

16. Kang JH (2007) Salsolinol, a tetrahydroisoquinoline catechol neurotoxin, induces human $\mathrm{Cu}, \mathrm{Zn}$-superoxidie dismutase modificaiton. J Biochem Mol Biol 40, 684-689

17. Rouault TA and Cooperman S (2006) Brain iron metabolism. Semin Padiatr Neurol 13, 142-148

18. Harris ZL, Takahashi Y, Miyajima H et al (1995) Aceruloplasminemia: molecular characterization of this disorder of iron metabolism. Proc Natl Acad Sci U S A 92, 2539-2543

19. Kim KS, Choi SY, Kwon HY et al (2002) The ceruloplasmin and hydrogen peroxide system induces alpha-synuclein aggregation in vitro. Biochimie 84, 625-631

20. Boll MC (2008) Free copper, ferroxidase and SOD1 activities, lipid peroxidation and $\mathrm{NO}(\mathrm{x})$ content in the CSF. A different marker profile in four neurodegenerative diseases. Neurochem Res 33, 1717-1723

21. Boll MC, Sotelo J, Otero E et al (1999) Reduced ferroxidase activity in the cerebrospinal fluid from patients with Parkinson's disease. Neurosci lett 265, 155-158 
22. Olivieri S, Conti A, lannaccone $S$ et al (2011) Ceruloplasmin oxidation, a feature of Parkinson's disease CSF, inhibits ferroxidase activity and promotes cellular iron retention. J Neurosci 31, 18568-18577

23. Martinez-Hemandez R, Montes S, Higuera-Calleja J et al (2011) Plasma ceruloplasmin ferroxidase activity correlates with the nigral sonographic area in Parkinson's disease patients: a pilot study. Neurochem Res 36, 2111-2115

24. Bharucha KJ, Friedman JK, Vincent AS and Ross ED (2008) Lower serum ceruloplasmin levels correlate with younger age of onset in Parkinson's disease. J Neurol 255, 1957-1962

25. Torsdottir G, kristinsson J, Sveinbjornsdottir S et al (1999) Copper, ceruloplasmin, superoxide dismutase and iron parameters in Parkinson's disease. Pharmacol Toxical 85, 239-243

26. Jin L, Wang J, Zhao L et al (2011) Decreased serum ceruloplasmin levels characteristically aggravate nigral iron deposition in Parkinson's disease. Brain 134, 50-58

27. Jin L, Wang J, Jin $\mathrm{H}$ et al (2012) Nigral iron deposition occurs across motor phenotypes of Parkinson's disease. Eur J Neurol 19, 969-976

28. Torsdottir G, Sveinbjornsdottir S, Kristinsson J et al (2006) Ceruloplasmin and superoxide dismutase (SOD1) in Parkinson's disease: a follow-up study. J Neurol Sci 241, 53-58

29. Osaki S, Johnson DA and Frieden E (1966) The possible significance of the ferrous oxidase activity of ceruloplasmin in normal human serum. J Boil Chem 241, 2746-2751

30. Levine RL, Williams JA, Stadtman ER and Shacter E (1994) Carbonyl assays for determination of oxidatively modified proteins. Methods Enzymol 233, 346-357

31. Kang JH (2004) Modification of $\mathrm{Cu}, \mathrm{Zn}$-superoxide dismutase by oxidized catecholamines. J Biochem Mol Biol 37, 325-329

32. Kim SM and Kang JH (1997) Peroxidative activity of human Cu,Zn-superoxide dismutase. Mol Cells 7, 120-124

33. Choi SY, Kwon HY, Kwon OB and Kang JH (1999) Hydrogen peroxide-mediated $\mathrm{Cu}, \mathrm{Zn}$-superoxide dismutase fragmentation: protection by carnosine, homocarnosine and anserine. Biochim Biophys Acta 1472, 651-657

34. Halliwell B and Gutteridge JMC (2007) Free Radicals in Biology and Medicine, Oxford, New York.

35. Davies KJ, Delsignore ME and Lin SW (1987) Protein damage and degradation by oxygen radicals. II. Modification of amino acids. J Biol Chem 262, 9902-9907

36. Goldstein S and Czapski G (1987) Mechanism of reduction of bleomycin- $\mathrm{Cu}(\mathrm{II})$ by $\mathrm{CO}_{2}$ - and oxidation of bleomycin- $\mathrm{Cu}(\mathrm{l})$ by $\mathrm{H}_{2} \mathrm{O}_{2}$ in the absence and presence of DNA. Int J Radiation Biol Related Stud Phys Chem Med 51, 693-706

37. Gutteridge JM and Halliwell B (1982) The role of the superoxide and hydroxyl radicals in the degradation of DNA and deoxyribose induced by a copper-phenanthroline complex. Biochem Pharmacol 31, 2801-2805

38. Imlay JA, Chin SM and Linn S (1988) Toxic DNA damage by hydrogen peroxide through the Fenton reaction in vivo and in vitro. Science 240, 640-642

39. Schweigert N, Zehnder AJ and Eggen RI (2001) Chemical properties of catechols and their molecular modes of toxic action in cells, from microorganisms to mammals. Environ Microbiol 3, 81-91

40. Li Q, Aubrey MT, Christion T and Free BM (1997) Differential inhibition of DNA synthesis in human T cells by the cigarette tar components hydroquinone and catechol. Fundam Appl Toxicol 38, 158-165

41. Zaitseva I, Zaitsev V, Card G et al (1996) The X-ray structure of human serum ceruloplasmin at $3.1 \AA$ : nature of the copper centres. J Biol Inorg Chem 1, 15-23

42. Malmstom BG (1982) Enzymology of oxygen. Ann Rev Biochem 51, 21-59

43. Bento I, Peixoto C, Zaisev VN and Lindley PF (2007) Ceruloplasmin revisited: structural and functional roles of various metal cation-binding sites. Acta Cryst 63, 240-248

44. Choi SY, Kwon HY, Kwon OB et al (2000) Fragmentation of human ceruloplasmin induced by hydrogen peroxide. Biochimie 82, 175-180

45. Kang JH, Kim KS, Choi SY et al (2001) Oxidative modification of human ceruloplasmin by peroxyl radicals. Biochim Biophys Acta 1568, 30-36

46. Montes S, Rivera-Mancia S, Diaz-Ruiz A, Tristan-Lopez L and Rios C (2014) Copper and copper proteins in Parkinson's disease. Oxid Med Cell Longev 2014, 147251-147266

47. Surh YJ, Jung YJ, Jung JH, Lee JS and Yoon HR (2002) Iron enhancement of oxidative DNA damage and neuronal cell death induced by salsolinol. J Toxicol Environ Health Part A $65,473-488$

48. Jung YJ and Surh YJ (2001) Oxidative DNA damage and cytotoxicity induced by copper-stimulated redox cycling of salsolinol, a neurotoxic tetrahydroisoquinoline alkaloid. Free Radic Biol Med 30, 1407-1417

49. Wanpen S, Govitrapong P, Shavali S, Sangchot PM and Ebadi M (2004) Salsolinol, a dopamine-derived tetrahydroisoquinoline, induces cell death by causing oxidative stress in dopaminergic SH-SY5Y cells, and the said effect is attenuated by metallothionein. Brain Res 1005, 67-76

50. Maruyama W, Sobuc G, Matsubara K et al $(1997)$ A dopaminergic neurotoxin, $1(\mathrm{R}), 2(\mathrm{~N})$-dimethyl-6,7-dihydroxy1,2,3,4-tetrahydro-isoquinoline, $\mathrm{N}$-methyl $(\mathrm{R})$ salsolinol, and its oxidation product, 1,2(N)-dimethyl-6,7-dihydroxyisoquinolinium ion, accumulate in the nigro-striatal system of the human brain. Neurosci Lett 223, 61-64

51. Maruyama $W$, Abe T, Tohgi $H$, Dostert $P$ and Naoi $M$ (1996) A dopaminergic neurotoxin, (R)-N-methylsalsolinol, increases in Parkinsonian cerebrospinal fluid. Ann Neurol 40, 119-122

52. Smith PK, Krohn RI, Hermanson GT et al (1985) Measurement of protein using bicinchoninic acid. Anal Biochem $150,76-85$

53. Laemmli UK (1970) Cleavage of structural proteins during the assembly of the head of bacteriophage T4. Nature 227, 680-685

54. Sato M, Gitlin JD (1991) Mechanisms of copper incorporation during the biosynthesis of human ceruloplasmin. J Biol Chem 266, 5128-5134

55. Kang JH (2013) Modification and inactivation of $\mathrm{Cu}, \mathrm{Zn}$-superoxidee dismutase. BMB Rep 46, 555-560

56. Levine RL (1982) Rapid benchtop method of alkaline hydrolysis of proteins. J Chromatogr 236, 496-498 